\title{
Mechanical Properties of Porous Ti-6Al-4V Alloys Prepared by Selective Laser Melting and Post-heat Treatments
}

\author{
Ping-Win Lui, ${ }^{1}$ Chun-Ming Chang, ${ }^{2}$ Huai-Hsien Wang, ${ }^{3}$ \\ Yu-Ping Lin, ${ }^{3}$ and Feng-Min Lai ${ }^{3 *}$ \\ ${ }^{1}$ Taichung Veierans General Hospital, \\ No. 1650, Sec. 4, Taiwan Blvd., Situn Dist., Taichung City 40705, Taiwan (R.O.C.) \\ ${ }^{2}$ Instrument Technology Research Center, \\ No. 20, Yanfa 6th Rd., East Dist., Hsinchu City 30076, Taiwan (R.O.C.) \\ ${ }^{3}$ Bachelor Program for Design and Materials for Medical Equipment and Devices, Da-Yeh University, \\ No. 168, Syuefu Rd., Dacun Township, Changhua County 51591, Taiwan (R.O.C.)
}

(Received May 31, 2019; accepted October 28, 2019)

Keywords: porous, Ti-6Al-4V alloys, selective laser melting, heat treatment, strength

In this study, porous Ti-6Al-4V alloys were prepared by selective laser melting (SLM), and post-heat treatments were also performed on as-built alloys. The effects of post-heat treatments on the microstructural and textural properties of SLM-prepared porous Ti-6Al-4V alloys were investigated in detail. In our work, porous Ti-6Al-4V alloys were fabricated by SLM with two built directions. During the SLM process, the hatching distance, hatching power, rotation angle, exposure time, and point distance were kept at $0.065 \mathrm{~mm}, 200 \mathrm{~W}, 67^{\circ}, 50 \mu \mathrm{s}$, and $75 \mu \mathrm{m}$, respectively. The post-heat treatments were performed in a vertical tube furnace for $2 \mathrm{~h}$ with a heating rate of $10^{\circ} \mathrm{C} / \mathrm{min}$, and temperatures of $500,700,884,950,1000$, and $1050^{\circ} \mathrm{C}$ were used in these treatments. After these treatments, the samples were cooled in air. The microstructural and textural properties of as-built and heat-treated porous Ti-6Al-4V alloys were analyzed in detail. The textural properties were observed by optical and scanning electron microscopies. More detailed analysis results regarding the use of these alloys in medical porous implants will be presented in the future. The porous sample subjected to post-heat treatment at $500{ }^{\circ} \mathrm{C}$ had the lowest Young's modulus (34.372 GPa) and the highest tensile strength $(259.6 \mathrm{MPa})$, which were close to those of human bone.

\section{Introduction}

Because of their good mechanical properties, low density, superior biocompatibility, and exceptional corrosion resistance, porous $\mathrm{Ti}-6 \mathrm{Al}-4 \mathrm{~V}$ alloy materials have attracted much interest. Thus, a large number of applications of porous Ti-6Al-4V alloys including those in the aerospace, medical implant, and automotive industries have been extensively developed. It is well known that the conventional manufacturing methods are not efficient in preparing porous

*Corresponding author: e-mail: fengmin@mail.dyu.edu.tw https://doi.org/10.18494/SAM.2019.2507 
Ti-6Al-4V alloys for wider applications. Fortunately, a layer-wise additive manufacturing (AM) technique that has many advantages such as high geometrical flexibility, shorter lead time, cost saving, and efficient use of materials has been proposed in recent years. By using the AM fabrication process, the usage of Ti-6Al-4V alloys can be broadened efficiently. ${ }^{(1)}$ Among the various additive manufacturing techniques for alloy materials, selective laser melting (SLM) is one of the most promising methods. ${ }^{(2-5)}$ Compared with conventional production methods, there are several advantages of SLM, such as high geometrical flexibility, simple production process, near-net-shape production, and efficient use of materials. More importantly, owing to the layer-wise building process, the production of parts with a high geometrical complexity can be achieved by SLM. Up to now, SLM has been one of the commonly used AM methods to fabricate Ti-6Al-4V alloys. Moreover, to our knowledge, post-heat treatments can be employed to improve the mechanical properties of $\mathrm{Ti}-6 \mathrm{Al}-4 \mathrm{~V}$ alloys, and the variations of mechanical properties are strongly related to the changes in microstructural and textural characteristics. In this study, Ti-6Al-4V alloys were prepared by SLM, and post-heat treatments were also performed on the as-prepared alloys. The effects of post-heat treatments on the microstructural and textural properties of SLM-prepared Ti-6Al-4V alloys were investigated in detail. Several alloy materials with good mechanical characteristics can be achieved by SLM, especially Ti-6Al-4V alloys. In biomedical industries, Ti-6Al-4V alloys have received much attention, particularly for implant applications, and many implant devices, including pacemakers, cardiac valve prostheses, screws for fracture fixation, bone plates, artificial hearts, artificial knee joints, and artificial hip joints, have been fabricated using Ti-6Al-4V alloys. In addition, owing to the good characteristics of Ti-6Al-4V alloys, they can also be used to fabricate various sensor devices, such as optical fiber sensors, biosensors, piezoelectric force sensors, and acoustic emission sensors. Regardless of whether Ti-6Al-4V alloys are employed for biomedical or sensor applications, their mechanical properties are important for expanding their service lifetime. Thus, in this study, we have examined the mechanical properties of SLM-prepared Ti-6Al-4V alloys.

Although SLM is a mature technique for preparing Ti-6Al-4V samples, some innovative technologies are proposed in this study. First, the design of the pore arrangement to fabricate porous $\mathrm{Ti}-6 \mathrm{Al}-4 \mathrm{~V}$ has seldom been addressed. To our knowledge, the design of pore features in the front and side of $\mathrm{Ti}-6 \mathrm{Al}-4 \mathrm{~V}$ is rare. Along with the pore size and arrangement, the mechanical properties of Ti-6Al-4V samples can be modified efficiently. Secondly, there have been very few studies on the effects of heat treatments on SLM-prepared porous Ti-6Al-4V samples. For an appropriate pore design and the heat treatment, the Young's modulus of a Ti-6Al-4V sample is close to that of human bone, and its tensile strength can also be improved. We carried out heat treatments to determine the temperatures at which failure surfaces change and discussed the elongation results. The innovative technologies presented in this research can be applied so that SLM-prepared porous Ti-6Al-4V with an appropriate heat treatment has high potential for use in orthopedic implants. 


\section{Materials and Methods}

\subsection{Preparation of Ti-6Al-4V samples}

In our work, porous $\mathrm{Ti}-6 \mathrm{Al}-4 \mathrm{~V}$ alloys were fabricated by SLM with two built directions, which were defined as the narrow- and wide-horizontal directions, as shown in Fig. 1 (the size of the porous $\mathrm{Ti}-6 \mathrm{Al}-4 \mathrm{~V}$ alloy samples is indicated in the figure). Note that there have been very few studies that have compared the characteristics of porous $\mathrm{Ti}-6 \mathrm{Al}-4 \mathrm{~V}$ alloys prepared with the narrow- and wide-horizontal directions.

\subsection{Heat treatment}

In our work, porous Ti-6Al-4V alloy samples (shown in Fig. 2) were prepared by SLM, and post-heat treatments were performed in a vertical tube furnace for $2 \mathrm{~h}$ with a heating rate of $10{ }^{\circ} \mathrm{C} / \mathrm{min}$. In addition, various temperatures were used in the post-heat treatments. To measure the Young's modulus and tensile strength of the porous Ti-6Al-4V alloy samples, a tensile testing machine was used.

\subsection{Characterization measurements}

Temperatures of $500,700,884,950,1000$, and $1050{ }^{\circ} \mathrm{C}$ were used in the post-heat treatments in a vertical tube furnace. After the heat treatments, the samples were cooled in air. The microstructural and textural properties of as-built and heat-treated porous $\mathrm{Ti}-6 \mathrm{Al}-4 \mathrm{~V}$ alloys were analyzed in detail. The crystal structures of these samples were investigated by X-ray diffraction (XRD). Textural properties were observed using a tensile testing machine, by scanning electron microscopy (SEM), and by optical microscopy. More detailed analysis results will be presented in the future.

\section{Narrow-horizontal}

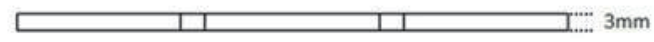

\section{Wide-horizontal}

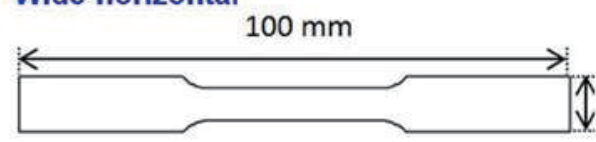

$10 \mathrm{~mm}$

Fig. 1. (Color online) Schematic diagrams of Ti$6 \mathrm{Al}-4 \mathrm{~V}$ alloys fabricated by SLM with narrow- and wide-horizontal directions.

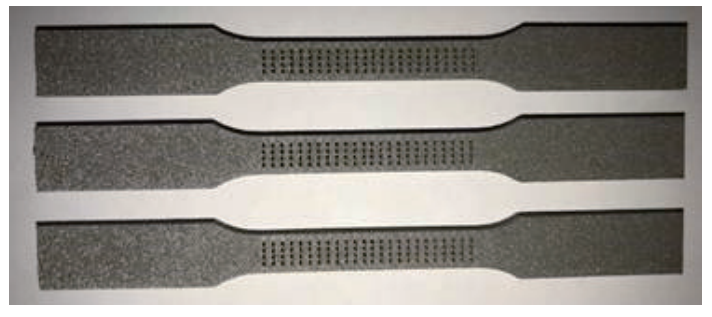

(a)

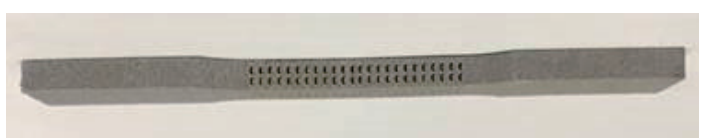

(b)

Fig. 2. (Color online) (a) Plan view of porous Ti6Al-4V alloy samples and (b) lateral side of a sample. 


\section{Results and Discussion}

\subsection{SEM Observations of tensile fracture sections}

The observations of tensile fracture sections of the as-built and heat-treated Ti-6Al-4V samples were performed by SEM, as shown in Figs. 3-5. The tensile fracture sectional images of the as-built and $500{ }^{\circ} \mathrm{C}$-treated samples are shown in Figs. 3(a) and 3(b), respectively. We can see that a quasi-split surface and incompletely melted powder existed in the sample, with the appearance of defects that had pulled away from the sides [Fig. 3(a)]. It was found that the tensile fracture section had many quasi-stubble surfaces, which were also covered with dimples. The dimples had a small diameter, were shallow, and had low ductility [Fig. 3(b)].

After heat treatment at $700{ }^{\circ} \mathrm{C}$, incompletely melted powder, as well as a microporous feature, can also be seen [Fig. 4(a)]. The tensile fracture section of the $700{ }^{\circ} \mathrm{C}$-treated sample has a transgranular cracking feature [Fig. 4(a)]. However, the broken section of the 884 ${ }^{\circ} \mathrm{C}$-treated sample exhibits an intergranular rupture [Fig. 4(b)]. We can observe that the defect had been completely pulled out and was formed by the incompletely melted Ti-6Al-4V powder [Fig. 4(b)]. In this image, the test strip is covered with quasi-cleft surfaces of different sizes.

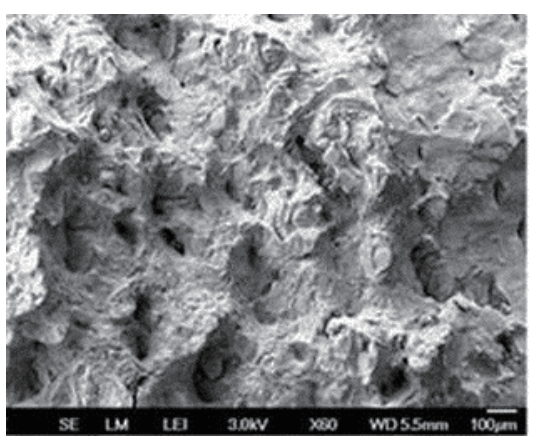

(a)

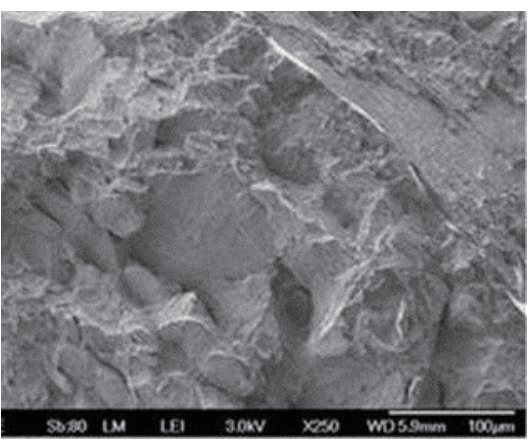

(b)

Fig. 3 SEM images of tensile fracture sections for (a) as-built and (b) $500{ }^{\circ} \mathrm{C}$-treated $\mathrm{Ti}-6 \mathrm{Al}-4 \mathrm{~V}$ samples.

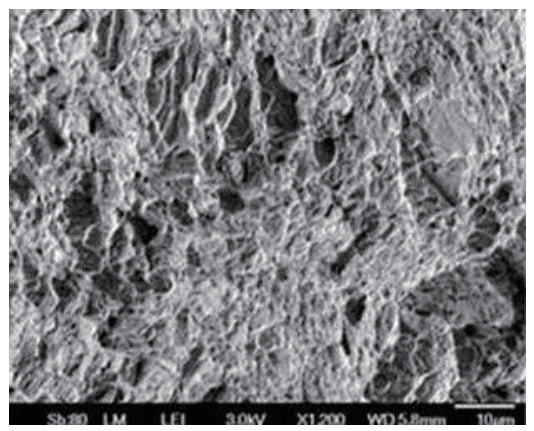

(a)

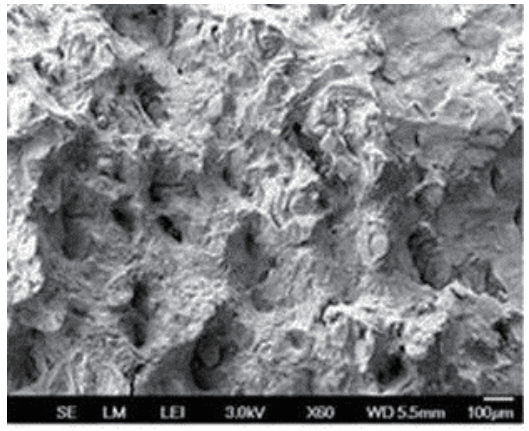

(b)

Fig. 4. SEM images of tensile fracture sections for (a) $700{ }^{\circ} \mathrm{C}$ - and (b) $884^{\circ} \mathrm{C}$-treated Ti-6Al-4V samples. 
Figure 5(a) shows the tensile fracture section of the $925{ }^{\circ} \mathrm{C}$-treated sample, which has many quasi-cleavage facets and microholes. The tensile fracture section of the $1000{ }^{\circ} \mathrm{C}$-treated sample shows a transgranular fracture under high-magnification observation [Fig. 5(b)]. The surface is covered with quasi-cleavage facets and microspores of different sizes.

\subsection{XRD diffraction patterns of SLM Ti-6AI-4V}

Figure 6 shows the XRD patterns of the SLM-prepared porous Ti-6Al-4V samples. It can be observed that there are only three diffraction peaks, $\alpha(100), \alpha(002)$, and $\alpha(101)$, in the XRD patterns of the as-built, $500{ }^{\circ} \mathrm{C}$-treated, and $700{ }^{\circ} \mathrm{C}$-treated samples. Because the heat treatment temperatures of 500 and $700{ }^{\circ} \mathrm{C}$ are very low, there is no diffraction peak of the $\beta$ phase in these samples. After the heat treatments at $884,925,1000$, and $1050{ }^{\circ} \mathrm{C}$, in addition to the three diffraction peaks of the $\alpha$ phase, the $\beta(110)$ diffraction peak also appears for these samples.

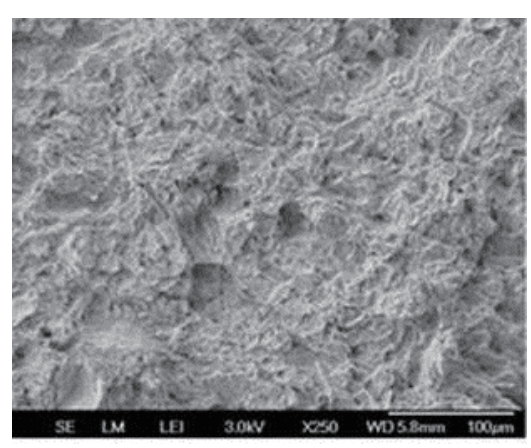

(a)

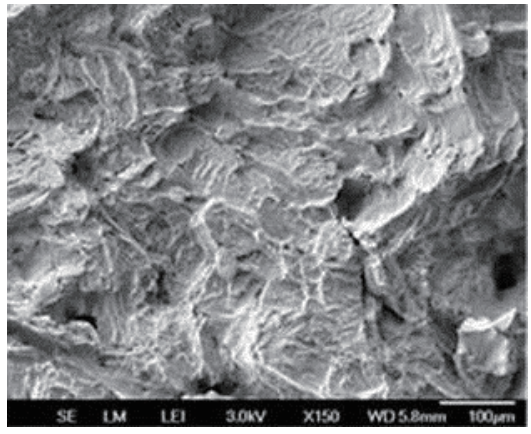

(b)

Fig. 5. SEM images of tensile fracture sections for (a) $925^{\circ} \mathrm{C}$ - and (b) $1000^{\circ} \mathrm{C}$-treated Ti-6Al-4V samples.

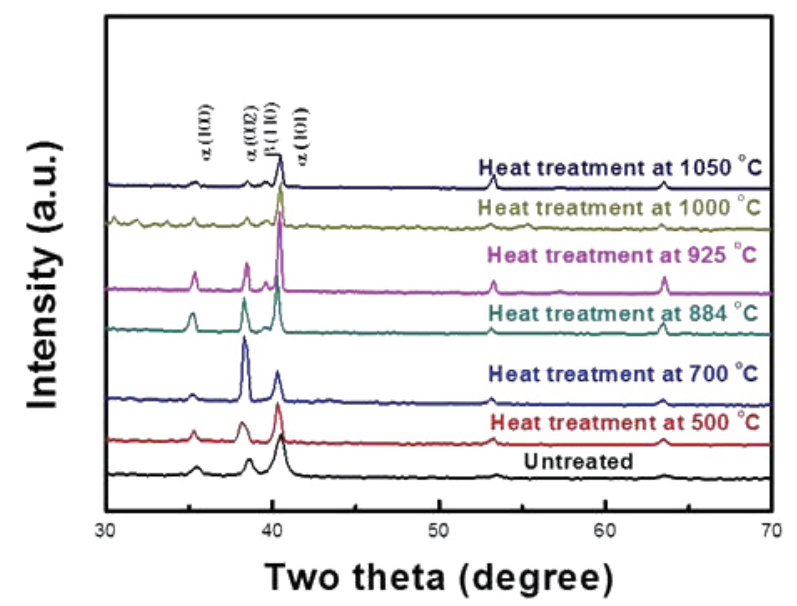

Fig. 6. (Color online) XRD patterns of SLM-prepared porous Ti-6Al-4V samples. 


\subsection{Effect of heat treatment on tensile strength}

Figure 7 shows the tensile strengths (measured by the tensile tests) of the as-built and heattreated Ti-6Al-4V samples. It was found that the tensile and fall strengths of these samples both decreased when the heat treatment temperature was increased.

\subsection{Mechanical properties of SLM-prepared Ti-6Al-4V samples}

The elongation (Fig. 8) and Young's modulus (Fig. 9) of the as-built and heat-treated Ti-6Al-4V samples are also discussed. As the heat treatment temperature increased, the elongation of the samples increased. It is also known that the heat treatment had little effect on Young's modulus. The Young's moduli of the as-built and heat-treated nonporous and porous Ti-6Al-4V samples were all measured. Table 1 shows the Young's moduli of these samples.

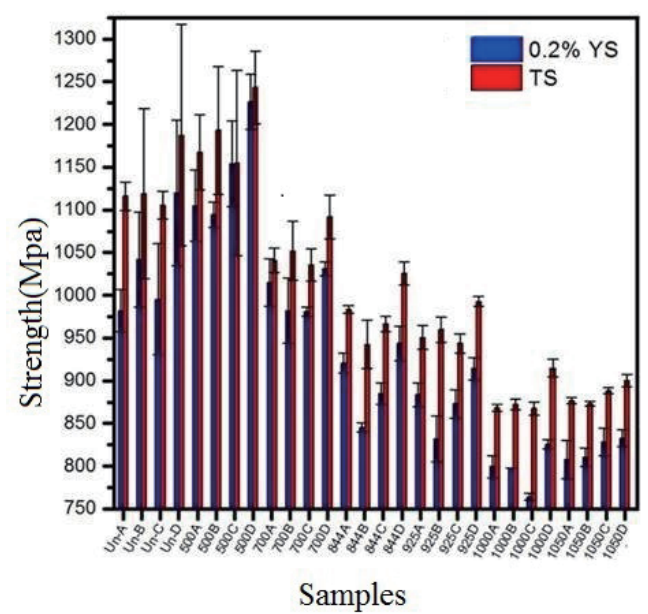

Fig. 7. (Color online) Effect of heat treatment temperature on tensile strength.

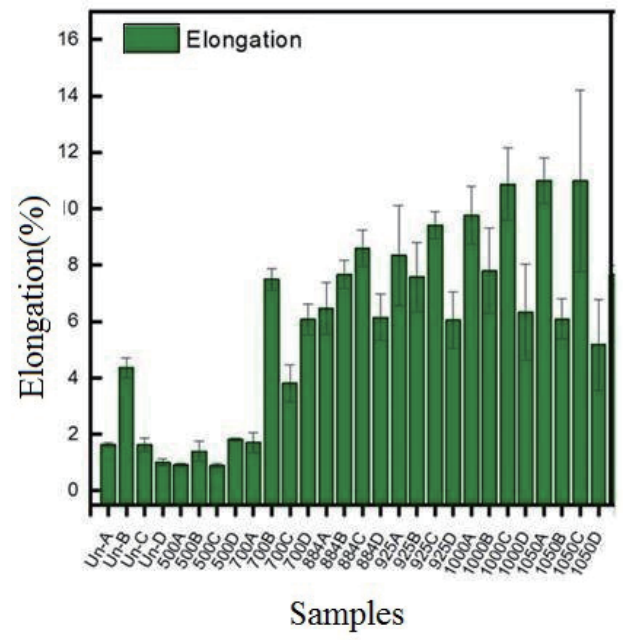

Fig. 8. (Color online) Elongation results of as-built and heat-treated $\mathrm{Ti}-6 \mathrm{Al}-4 \mathrm{~V}$ samples.

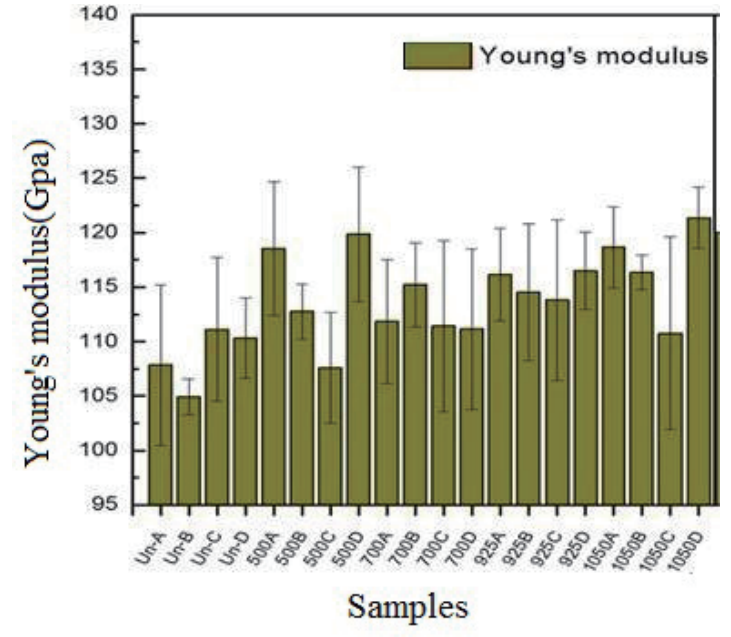

Fig. 9. (Color online) Young's moduli of as-built and heat-treated $\mathrm{Ti}-6 \mathrm{Al}-4 \mathrm{~V}$ samples. 
Table 1

Young's moduli of as-built and heat-treated nonporous and porous $\mathrm{Ti}-6 \mathrm{Al}-4 \mathrm{~V}$ samples.

\begin{tabular}{lcccc}
\hline & As-built & $500{ }^{\circ} \mathrm{C}$-treated & $700{ }^{\circ} \mathrm{C}$-treated & $1000{ }^{\circ} \mathrm{C}$-treated \\
\hline Nonporous & 114.58 & 118.38 & 111.778 & 109.91 \\
Porous & 34.269 & 34.372 & 40.205 & 39.16 \\
\hline
\end{tabular}

Note. The unit is GPa.

Table 2

Tensile strengths of as-built and heat-treated nonporous and porous $\mathrm{Ti}-6 \mathrm{Al}-4 \mathrm{~V}$ samples.

\begin{tabular}{llccc}
\hline & As-built & $500{ }^{\circ} \mathrm{C}$-treated & $700^{\circ} \mathrm{C}$-treated & $1000^{\circ} \mathrm{C}$-treated \\
\hline Nonporous & 800.53 & 889.72 & 894.28 & 725.25 \\
Porous & 200.31 & 259.6 & 244.9 & 169.41 \\
\hline
\end{tabular}

Note. The unit is MPa.

The nonporous sample subjected to heat treatment at $500{ }^{\circ} \mathrm{C}$ had the highest Young's modulus of $118.38 \mathrm{GPa}$, whereas the as-built and heat-treated porous samples all had markedly lower Young's moduli (34.269-40.205 GPa), which are close to that of human bone. Table 2 shows the tensile strengths of these samples. The nonporous sample subjected to heat treatment at 500 ${ }^{\circ} \mathrm{C}$ showed the highest tensile strength of $889.72 \mathrm{MPa}$. Among the porous samples, we observed the highest tensile strength of $259.6 \mathrm{MPa}$ in the $500{ }^{\circ} \mathrm{C}$-treated sample. Thus, the heat treatment at $500{ }^{\circ} \mathrm{C}$ is most effective for improving the mechanical properties of Ti-6Al-4V samples.

The alloys in this study are expected to be used in orthopedic implants. Since the porous Ti6Al-4V alloys have sufficient thickness and porosity with many holes and are lightweight, bone cells can grow in the pores. If the SLM-prepared Ti-6Al-4V alloy had no holes, its Young's modulus would be much higher than that of human bone, and stress concentration could easily occur at the joint of the bone and manufactured implant materials (bone plate and bone nail). Therefore, to solve the problem of stress concentration, we prepared porous Ti-6Al-4V alloys.

We have designed the diameter, spacing, and number of holes for porous Ti-6Al-4V alloys by SLM. Moreover, we have optimized the process temperature of the post-heat treatment. The results reveal that these porous Ti-6Al-4V alloys with a more suitable Young's modulus and a higher tensile strength can be applied to implant materials. The innovative technologies presented in our work allow us to confirm that SLM-prepared porous Ti-6Al-4V with a suitable heat treatment is very suitable for use in orthopedic implants.

\section{Conclusions}

In this study, the effects of heat treatment and pore design on the mechanical properties of SLM-prepared Ti-6Al-4V samples were discussed. The following are our conclusions:

1. Heat treatment can change the microstructure of a Ti-6Al-4V sample, affecting its mechanical properties. When a higher temperature is used in the heat treatment, a larger grain size can be obtained in the Ti-6Al-4V sample. According to the Hall-Petch relationship, a larger grain size can decrease the drop strength and hardness. Our work shows that the tensile strength also decreases as the grain size increases. Additionally, the elongation of the Ti-6Al-4V sample increases with the heat treatment temperature. 
2. Heat treatment at $500{ }^{\circ} \mathrm{C}$ is most effective for improving the mechanical properties of $\mathrm{Ti}-$ $6 \mathrm{Al}-4 \mathrm{~V}$ samples, which is probably due to the precipitation of the $\mathrm{Ti}_{3} \mathrm{Al}$ phase. However, the elongation of these samples was the lowest.

3. In SEM observations of tensile fracture sections, at the temperature of $500{ }^{\circ} \mathrm{C}$, we found that the tensile fracture section had many quasi-stubble surfaces, which were also covered with dimples. The dimples had a small diameter, were shallow, and had a low ductility. At the temperatures of 925 and $1000{ }^{\circ} \mathrm{C}$, less quasi-cleavage facets and microholes were observed. It can be seen that the flatness of the surface improves ductility and affects tensile strength.

4. The porous Ti-6Al-4V samples had lower Young's moduli than the nonporous samples. After the treatment at $500{ }^{\circ} \mathrm{C}$, the Young's modulus and tensile strength were close to those of human bone.

\section{Acknowledgments}

The authors would like to thank the Ministry of Science and Technology in Taiwan for financially supporting this research project under grant No. 103-2221-E-212-008.

\section{References}

1 S. Q. Wu, Y. J. Lu, Y. L. Gan, T. T. Huang, C. Q. Zhao, J. J. Lin, S. Guo, and J. X. Lin: J. Alloys Compd. 647 (2016) 643. https://doi.org/10.1016/j.jallcom.2016.02.183

2 T. Vilaro, C. Colin, and J. D. Bartout: Metall. Mater. Trans. 42 (2011) 3190. https://doi.org/10.1007/s11661-0110731-y

3 L. Thijs, F. Verhaeghe, T. Craeghs, J. V. Humbeeck, and J. P. Kruth: Acta Mater. 58 (2010) 3303. https://doi. org/10.1016/j.actamat.2010.02.004

4 B. Vrancken, L.Thijs, J. P. Kruth, and J. V. Humbeeck: J. Alloys Compd. 541 (2012) 171. https://doi. org/10.1016/j.jallcom.2012.07.022

5 M. Fousová, D. Vojtěch, J. Kubásek, E. Jablonská, and J. Fojt: J. Mech. Behave. Biomed. Mater. 69 (2017) 368. https://doi.org/10.1016/j.jmbbm.2017.01.043

\section{About the Authors}

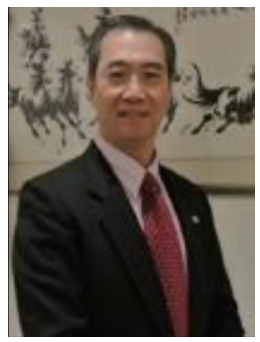

Ping-Win Lui received his B.S. degree from National Yang Ming University, Taiwan, in 1989 and his M.S. and Ph.D. degrees from National Yang Ming University, Taiwan, in 2002 and 2009, respectively. From 2008 to 2014, he was a dean at Taichung Veterans General Hospital Puli Branch, Taiwan. Since 2014, he has been an associate dean at Taichung Veterans General Hospital. His research interests are in anesthesia medicine, pain medicine, pharmacology, and patient safety. (superanesthesia@vghtc.gov.tw) 


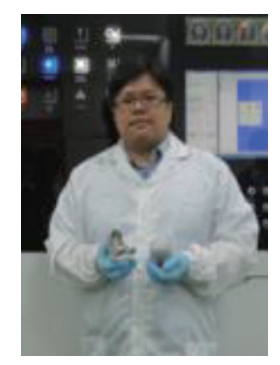

Chun-Ming Chang received his B.S., M.S., and Ph.D. degrees from Southern Taiwan University of Science and Technology, National Taiwan Normal University, and National Taiwan University, Taiwan, in 2001, 2006, and 2014, respectively. Since 2017, he has been an associate researcher at Instrument Technology Research Center, National Applied Research Laboratories, Taiwan. His research interests are in 3D printing, implant material research, and material science. (gmp@itrc.narl.org.tw)

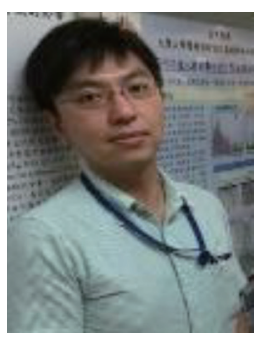

Huai-Hsien Wang received his B.S. degree from Da-Yeh University, Taiwan, in 2007 and his M.S. degree from the Da-Yeh Institute of Technology, Taiwan, in 2018. From 2016 to 2018, he was a researcher at Da-Yeh University. His research interests are in 3D printing, implant material research, and computer graphics. (R0590001@mail.dyu.edu.tw)

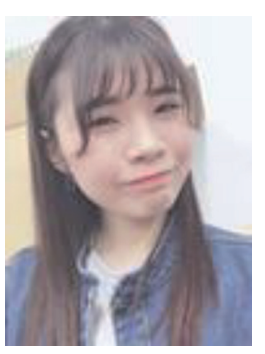

Yu-Ping Lin received her B.S. degree from Da-Yeh University, Taiwan, in 2019. From 2018 to 2019, she was a researcher at Da-Yeh University. Her research interests are in 3D printing, implant material research, and computer graphics. (my0115melody@gmail.com)

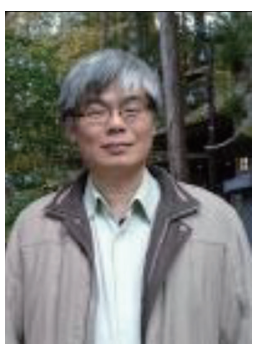

Feng-Min Lai received his B.S. degree from Chinese Culture University, Taiwan, in 1991 and his M.S. and Ph.D. degrees from the National Chiao Tung University, Taiwan, in 1993 and 1997, respectively. From 2002 to 2016, he was an associate professor at Da-Yeh University, Taiwan. Since 2017, he has been a professor at Da-Yeh University. His research interests are in composite materials, computer graphics, and medical aid development.

(fengmin@mail.dyu.edu.tw) 